\title{
The Status of Ethics in the Entrepreneurial Process
}

\author{
Taoufik Radouche ${ }^{1}$ \\ ${ }^{1}$ Department of Management, Higher Institute of Management, University of Sousse, Tunisia \\ Correspondence: Radouche Taoufik, ISG de Sousse, Rue Abdlaaziz il Behi . B.P. 763-4000 Sousse, Tunisia. Tel: \\ 216-9863-6202. E-mail: taoufikradouche@yahoo.fr
}

\author{
Received: March 18, 2013 \\ Accepted: April 1, 2014 \\ Online Published: May 22, 2014 \\ doi:10.5539/ijbm.v9n6p199 \\ URL: http://dx.doi.org/10.5539/ijbm.v9n6p199
}

\begin{abstract}
Operationalising the notion of ethics, along with its applications in the field of entrepreneurship, has made possible the investigation of the influence exerted by the socio-cultural, economic, and legal environment on entrepreneurs' ethical behavior while they engage in the process of entrepreneurship. The purpose of this research is to analyze the impact of socio-cultural, economic, and legal factors on the development of business ethics. On the other hand, we analyze the influence of the development of business ethics on the entrepreneurial process.

The population of the study contained 57 Tunisian young entrepreneurs in different sectors. In order to gathering the data required for measuring the study variables a questionnaire was developed. The results of the study showed that some personal traits as well as certain socio-cultural, economic, and legal factors influence their decision during the entrepreneurial process. It has been noticed that there are significant differences between the levels of development in the ethical orientation characterizing each phase of the entrepreneurial process. These differences are related to the entrepreneur's strategy, the organizational environment, and stakeholders' strategies.
\end{abstract}

Keywords: ethics, entrepreneurship, entrepreneurial process, business ethics, environment

\section{Introduction}

"The entrepreneurial process involves all the functions, activities, and actions associated with perceiving opportunities and starting up new organizations to pursue them" (Bygrave, 2010, p. 2). This process includes economic, legal, and socio-cultural factors. These dimensions have been studied intensively. Nonetheless, only the ethical factor remains under-researched. In fact, while being engaged in his/her professional vocation as entrepreneur, the latter is simultaneously perceived as a strategic actor (economic rationality), a citizen (both citizenship rights and duties), a socialized agent (sphere of socialization), and equally an individual endowed with reflexivity (personal ethics). Business ethics allow researchers to envisage the act of undertaking business as being a behavior guided by economic rationality or/and as an act of conformity with the laws and regulations in force, and also as a project affected by the entrepreneur's strategy, the organizational environment, and stakeholders' strategies. Therefore, the objective of this article is to investigate the way entrepreneurs implement these action logics in the entrepreneurial process. The conceptual framework developed through theoretical analysis has been validated by a survey conducted on a population of young Tunisian entrepreneurs.

\section{The Entrepreneurial Process and Ethics: Some Clarifications}

When engaged in an entrepreneurial process, the entrepreneur mobilizes various logics of action: (a) a socialization logic (reproduction of a family model), (b) a logic of economic rationality (rational behavior aiming at seizing opportunities), and (c) a logic of personal ethics (realization of an individual project which assigns meaning to the concept of work and the very existence of the entrepreneur) (Dubet, 1994). The entrepreneur's purpose is to justify his/her commitment to an entrepreneurship career. Hence, quite beyond its dimension of entrepreneurial socialisation and that of rationality maximizing opportunity-seizing, entrepreneurial action belongs to a subjective register which refers to the existence of genuine business ethics.

\subsection{Approaches to the Entrepreneurial Process}

The functions, the activities, and the actions related to the entrepreneurial process are analysed according to three approaches: economic and functional approach, traits approach, and management and process approach. 
According to the economic and functional approach, entrepreneurship encompasses the identification of opportunities in the economic system (Schumpeter, 1934). The perception and exploitation of new opportunities represent the core of all entrepreneurial action. On the other hand, the traits approach is based on the hypothesis that entrepreneurs are different individuals having personality traits and attributes which allow them to have a predisposition to perform entrepreneurial activities (Greenberger \& Sexton, 1988). Research works based on this approach are oriented towards the identification of traits, motivators, and psychological features which differentiate entrepreneurs from non-entrepreneurs. However, the management and process approach focuses on the analysis of entrepreneurs' interaction with the entrepreneurial situation which motivates them in an attempt to comprehend their behaviours and reactions (Shane \& Venkatraman, 2000).

(Learned, 1992; Shane \& Venkatraman, 2000; Shook, Priem \& McGee, 2003) proposed a four-phase model for the process of setting up an organization: intention, identification, exploration, and exploitation of opportunity. Bruyat (1993) described the entrepreneurial process as progressive and evolutionary in time. It has the following three phases: (i) triggering of the entrepreneurial process, (ii) entrepreneur's total commitment, and (c) survival $\&$ growth of the launched business. Each of these phases requires entrepreneurial skills and predispositions which influence the behaviors and reactions of entrepreneurs.

In the current piece of research, a holistic approach will be adopted. Such approach will account for economic factors (particularly identified opportunities), entrepreneurs' traits, motivators, psychological features, and the evolution of entrepreneurs' skills and predispositions in the entrepreneurial process. The main purpose is to study the factors affecting the entrepreneur's behaviors and decisions in each of the phases which constitute the entrepreneurial process: economic, legal, and socio-cultural factors.

\subsection{The Entrepreneurial Process: from the Individual and Organizational Dimension to the Stakeholders}

The foundational concepts of business ethics have emerged from a series of reflections contemplating the meaning of business since the 1960s, such as Corporate Social Responsibility and Corporate Social Responsiveness. The notion of business ethics has been further elaborated through the Stakeholders Approach (1980), the Theory of Social Contract (1990), the Virtue Ethics Approach (1990), the Integrity Approach (1990), Ethical Codes (1990), Institutional Government (1990), and Norm Standardization (ISO 9001; ISO 14000).

Ethics signifies reflection on the foundations and analysis of the sources which legitimize the values and standards underlying good practices. Reference to ethics leads to the idea that the individual has normativity resources, that is to say, a capacity for identification, comparison, and judgement in particular situations. Given their normative nature, ethics comprises a combination of norms and provides leading principles whose influence can orientate individual behavior. According to Wells and Schminke (2001); ethical behavior is to behave according to the system of ethical values. Managers and academicians seek ways to start up more ethical organizations. Conversely, an unethical behavior is defined by Baucus and Near (1991) as a behavior which is not normally respectable or which is legally forbidden.

Both ethical and unethical behaviors originate simultaneously in the socio-cultural environment as well as in regulatory rules. In reality, ethics take shape by virtue of the long process of socialization experienced by the individual. Ethical values are related to passions, emotions, and networks of social relationships (individuals, family, ethnic group, region, civil society, State, etc.). When applied to the field of entrepreneurship, ethics means a system of behavioral norms and values which orientate entrepreneurs' behavior during the entrepreneurial process in order to build and improve the relationship with the self, the others, and the corporation, which in turn aims at fostering good conduct of their actions. Thus, ethics in the field of entrepreneurship are analyzed at three levels: individual, organizational, and stakeholders.

At the individual level, several authors admit that individual traits have some influence on the development of the entrepreneur's ethical conduct. Referring to Kohlberg's (1981) works, individuals evolve in a sequential and unidirectional way through three levels of moral development composed of seven phases: pre-conventional, conventional, and post-conventional. According to (Lichtenstein, Smith, \& Torbert, 1995), the more the individual develop his/her ethical reasoning, the more he/she will tend to be aware of his/her own actions, to assume responsibility, and to face all the consequences resulting from those very actions.

At the organizational level, Maclagan (1998) considers that ethical development manifests itself in the development of vision, culture, strategies, leadership types, systems, processes, and corporate objectives, which together guarantee an "emancipating function". Thus, business ethics can be the object of intellectual consideration. Quite beyond its status as simple conformity to standards and values, it can be translated into concrete action within the organizational framework. 
The entrepreneur's actions are equally influenced by various stakeholders: capital-lenders (incubators, business support structures, training institution), customers, suppliers, competitors, employees, social networks (such as family, friends, counselors, and associations), and government. It is important that the entrepreneur tries as much as possible to constantly and most accurately determine the interactions of his/her business with stakeholders. Therefore, the entrepreneur has responsibilities towards each of the different stakeholders. He/she tends to insist on the ethical dimension in order to guide his/her business towards more constructive directions. Thus, ethical thinking goes beyond the limits of individual awareness to be propagated in the entire organization and its stakeholders. It constitutes a fundamental dimension to be reckoned with during the entrepreneurial process.

\section{The Development of Ethical Behavior during the Entrepreneurial Process: The Impact of Socio-Cultural, Economic and Legal Factors}

According to Gasse (2002), the environment where the individual lives has an influence on the choice of the entrepreneurial career as well as the decisions to be taken by potential entrepreneurs. The environment acts on entrepreneurs' ethical conduct during the entrepreneurial process. The subsections below will inspect the socio-cultural, economic, and legal environment which might exert some influence on entrepreneurs' actions.

\subsection{Socio-Cultural Factors}

The individual traits (age, gender, training, etc.) and the social network (residential address, etc.) generate norms and values which provide ideals, requirements, duties, and perspectives that are likely to orientate the entrepreneur's actions (Fayolle, 2005; Gasse \& Tremblay, 2006; Kolvereid \& Isaksen, 2006). These norms and values equip entrepreneurs with sufficiently legitimate points of reference which orientate the direction of behaviors along with the actions they engage throughout the entrepreneurial process. The perception of entrepreneurship as being a dynamic process of learning highlights the entrepreneur's idea of continual development of skills and knowledge to succeed in his/her entrepreneurial process.

The development of entrepreneurial skills can promote ethical behavior if they underscore the moral values of honesty and efficiency. The socio-cultural environment generates collective mental constructs or frames which influence entrepreneurs' behavior. Hofstede (1980) discussed national culture as a mode of mental programming for entrepreneurs' behavior. His empirical research on differences among national cultures resulted in four dimensions of cultural difference: power distance, collectivism versus individualism; femininity versus masculinity; and uncertainty avoidance.

Attachment to religious and spiritual values (Martin \& Novicevic, 2010) represents a socio-cultural factor which affects the maintenance of ethical behavior insofar as religious precepts determine the rules of conduct and inspire entrepreneurs with certain options. The aspiration to maintain ethical standards equally leads entrepreneurs to adopt an ethical code. This will allow the specification of ethical guidelines for behavior with which collaborators and stakeholders should align themselves (Nitkin \& Brooks, 1998).

Thus, hypothesis (H1) reads as follows: The development of ethical orientation at the level of the individual, the organization, and the stakeholders is affected by the attitudes as well as the models of behavior inherent in the entrepreneur's socio-cultural environment.

\subsection{Economic Factors}

The analysis of the economic environment shows that the transparency of administrative agencies and donors (incubators, business support structures, financial partners, support agencies, local authorities, etc.) allows the detection of all types of unethical act or behavior (Nordin, Takim, \& Nawawi, 2012). Adherence to the rules of fair competition manifests itself forcefully in order to eliminate all forms of undue privilege or favoritism. The implementation of a quality assurance process encourages accountability and self-inspection, that is to say, taking the right decisions. The promotion of Corporate Social Responsibility (CSR) encourages entrepreneurs to incorporate social, environmental and economic concerns in their business activities and those pertaining to their stakeholders on a voluntary basis (Wood, 1991). The CSR must encourage the promotion of ethical behavior with stakeholders.

These economic factors which unfavorably affect the maintenance of ethical behavior reveal the importance of promoting interpersonal relations which are based on the principles of integrity, fairness, and professional ethics. This gives rise to the formulation of hypothesis (H2): The economic environment has a decisive impact on the development of the ethical orientation at the individual, organizational, and stakeholders' levels.

\subsection{Legal Factors}

The institutional environment, and more particularly regulatory rules, can contribute to supporting 
entrepreneurship. Mayer-Schönberger (2010) has developed a theoretical framework that can explain the role of regulation in supporting entrepreneurship. It consists of a support structure for entrepreneurship allowing entrepreneurs to test the sustainability of their project of launching business as trainer on a probationary basis, which exempts them facing social, financial, and family risks and allows them to benefit from support, training, and assistance in terms of logistics, finance, and accounting. Mayer-Schönberger (2010) has proposed the concept of "entrepreneurial regulation", which means that the legislator must make regulations which aim at promoting the establishment of business firms, which represents an important decision. This regulatory logic seeks to realize transparency and avoid penalizing innovation and risk-taking. It penalizes any form of abusive behavior.

The highly regulated and sometimes excessively strict functioning of public administration leads to bureaucratic malfunctioning causing projects of launching new businesses to be entangled in intricate processes and virtually blockading them. This bureaucracy-oriented administrative culture can be seen as an intrinsic variable in strong correlation with non-compliance with certain ethical standards. This factor leads to the rejection of personal initiative.

The analysis of legal factors allows the formulation of the third research hypothesis (H3) stipulating that the legal environment affects the development of the ethical orientation of the entrepreneurs, the organization, and the stakeholders.

\section{The Conceptual Model}

The process of business creation as conceived by Bruyat (1993) has been revisited in order to validate the research hypotheses. It posits the following three phases: triggering the entrepreneurial process, entrepreneur's commitment, and survival-growth of the launched business. This process allows a better understanding of the influence of entrepreneurs' ethical and unethical behaviors on their actions during the act of starting up a new business.

Socio-cultural, economic, and legal environment influence the development of entrepreneurial ethical thinking. The study of the relationship between socio-cultural, economic, and legal values on the one hand; and the entrepreneurial process, on the other hand, allows the emergence of the interaction between beliefs, motivators, and behavior, which accounts for proceeding to action (cf. figure 1 below).

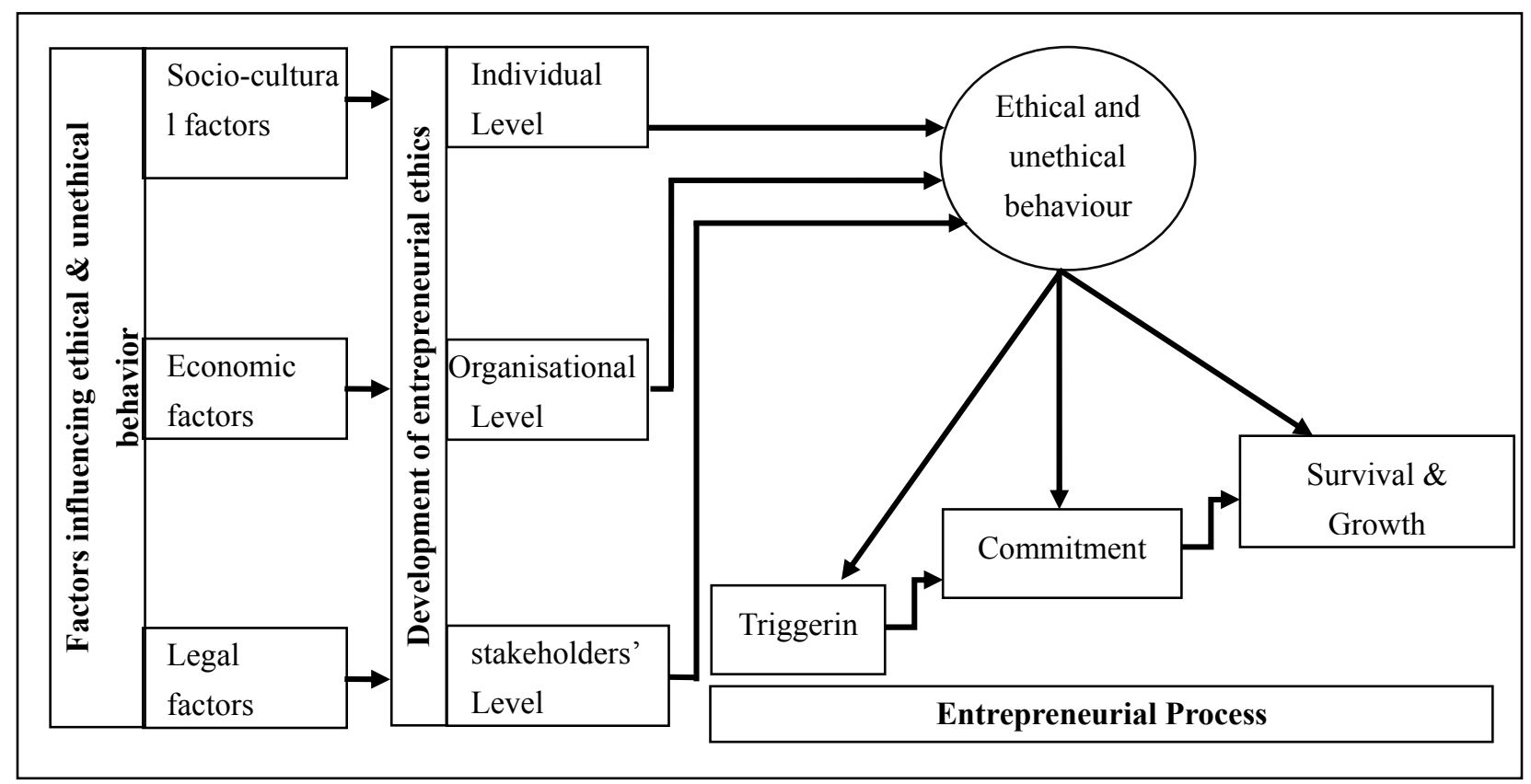

Figure 1. Theoretical model: development of the ethical orientation and entrepreneurial process

The entrepreneurial process is transformed into a process of dynamic learning and appropriation with a cumulative effect adding up socio-cultural, economic, and legal values. Such values, whose nature and importance vary from one phase to the other in the entrepreneurial process, orientate the entrepreneur's behavior. 
This allows us to advance the following hypothesis (H4): Evolution in the entrepreneurial process requires the development of ethical orientation at the level of the individual, the organization, and the stakeholders.

\section{Methodological Procedures}

Taking into account the above-formulated research hypotheses, we are concerned in this study with a population of young entrepreneurs who still remember the functions, the activities, and the actions related to the perception of opportunity and the follow-up of their projects. Data are collected directly from a sample of young entrepreneurs. The purpose is to analyze the impact of socio-cultural, economic, and legal factors on the development of the ethical orientation in each of the phases which constitute the entrepreneurial process.

The methodology retained consists in correlating the socio-cultural, economic, and legal variables with the levels of development associated with the ethical orientation (levels of individual, organization, and stakeholders) as well as the phases of the entrepreneurial process ((i) triggering of the entrepreneurial process, (ii) entrepreneur's total commitment, and (c) survival-growth of the launched business).

\subsection{Presentation of the Survey}

The research hypotheses have been tested in the Tunisian context. A survey was conducted on a sample of 57 young entrepreneurs in different sectors. It was implemented via a questionnaire dealing with the development of ethical and unethical behavior during the process of entrepreneurial process. The questionnaire comprises four parts. Part 1 is related to the triggering of the entrepreneurial process. Its aim is to examine the choice of the entrepreneurial career. The questions are about the professional situation of the respondents before their engagement in the entrepreneurial process and the reasons motivating their choice of the entrepreneurial process. Part 2 in the questionnaire contains questions related to the commitment phase in the entrepreneurial process. It handles the features of the entrepreneur and his/her business enterprise, in addition to information about funding sources, the preparation of a business plan, the difficulties encountered, and the determination of young entrepreneurs. Part 3 is related to the development phase. The questions are about the regulatory factors affecting decisions, the position of the firm, and the criteria of evaluating the firm's performance. This part explores the entrepreneur's perception of the relations with partners, the difficulties encountered while promoting his/her business enterprise, and the problems pertaining to moral principles. Part 4 deals with the personal data of the entrepreneur (socio-demographic data, qualifications, and social network).

The questionnaire was administered in the form of a semi-structured interview comprising questions which are easy to answer. Interviewees responded to all measurement items using a 5-point Likert-type scale (from strongly disagree to strongly agree). The questionnaire piloting targeted seven young entrepreneurs, which led to some necessary modifications required for drafting its final version and ensuring the smooth running of the ensuing interviews.

\subsection{Methods of Data Analysis}

The analysis of collected data was carried out in two phases. First, the analysis of data related to the sampling structure was carried out by Descriptive Analysis using the SPSS (20) software. Then, the analysis of the factors affecting the development of ethical behavior during the entrepreneurial process was performed by the XLSTAT-Pro (2013) software. It comprises two phases: the first phase is exploratory. It consists in purifying measures by Principal Component Analysis (PCA) and testing their reliability by calculating Cronbach's $\alpha$ value. This exploratory factor analysis is applied to all latent variables. The second phase is the confirmatory factor analysis. It consists in confirming the factor structure obtained from PCA analysis and testing the research hypotheses through Structural Equation Modeling (SEM).

\section{Structure of the Sample}

Concerning age, the respondents belong to the age-group 26-30,59\%. They are young entrepreneurs who on average started their business projects four years ago and therefore can remember all the phases and the circumstances of launching their own firms. The majority of respondents are males $(78.9 \%)$ where the rest are females $(21.1 \%)$. The number of surveyed female entrepreneurs is relatively limited because of the difficulty to find respondents from this category and also due to the refusal of some of them to respond to the survey questions. Their response to the questionnaire is important insofar as it would allow the identification of the discriminatory factors associated with the entrepreneurial process. The proportion of married entrepreneurs is $56.1 \%$. The category of single entrepreneurs comprises a majority of males aged below 30 . At this level, we can raise the question of whether this is a social phenomenon, because it is common knowledge that marriage allows the widening of the entrepreneur's social network.

The majority of respondents live in the eastern area of the country $(64.9 \%)$. They have high qualifications 
(57.9\%) and have received training in professional centers (36.8\%). They graduated in diverse specialized areas, such as management, catering, pastry, agriculture, and computers, etc.). Fifty-four point four percent (54.4\%) of the respondents (both males and females) work in the private sector. However, those who left the public sector to launch their own business are males. This implies that women are more attracted by a professional career as employee in the public sector, and that it rare to find women who are willing to quit their job in the public sector in order to set up their own business projects. The surveyed entrepreneurs who acquired professional experience through training specially designed for initiating novice job applicants represent $29.8 \%$ of the population sample. This special training is called SIVP in Tunisia (Training for Initiation to Professional Life).

Their quitting is first explained by the termination of their SIVP contract. Their option of launching their own business is mainly explicable by the absence of any hope to find a satisfactory job as salaried employee. The majority of respondents consider that accepting a salaried position in either the private or the public sector is only an occasion for seizing a business opportunity and improving their professional network. Others have opted for setting up their own business to improve their income, avoiding the difficulties encountered by salaried employees, and practice their area of specialism. The surveyed sample is considered to belong to the category of young entrepreneurs since the age of their business $(80.7 \%)$ does not exceed four years. They tend to launch their business projects essentially in the sector of retail trade $(43.9 \%)$, artisanal craftsmanship $(26.3 \%)$, and services (26.3\%). They are generally micro-businesses employing less than five staff members $(80.7 \%)$.

\section{Results}

The aim of this section is to present the findings of the both the exploratory and the confirmatory phases. It consists in testing the reliability of retained values and verifying the hypotheses presented in the research model.

\subsection{The Exploratory Phase}

Latent variables are retained with reference to the research model introduced in figure 1 . The measurement indicators of these variables are conceived on the basis of the literature reviewed earlier in this article. The variables are measured by various indicators (displayed in table 2). The correlation matrix displays the significance of coefficients. The analyses carried out during this exploratory phase allow us to purify the measurement indicators of latent variables. The purpose is to ensure the reliability of those variables.

\subsection{The Confirmatory Phase}

Structural Equation Modeling (SEM), particularly the Partial Least Squares Path Modelling (PLS), is used for testing the research hypotheses.

\subsubsection{Adjustment of the Model}

According to the PLS approach, the Goodness-of-Fit (GoF) index is used as an indicator of overall verification of adjustment quality (Vinzi, Trinchera, \& Amato, 2010). The computation of the GoF values (cf. Table 1) shows that comparative GoF and those based on internal and external models are high and also tend to translate a good quality of model adjustment to the data. The PLS approach favors the external model $(0.968)$ which measures the correlation between latent variables and their respective indicators rather than the internal model (0.684) which emphasizes the estimation of relations between the latent variables.

Table 1 . Adjustment quality of the model

\begin{tabular}{ll}
\hline GoF & Value \\
\hline Absolute & 0.502 \\
Relative & 0.661 \\
External Model & 0.968 \\
Internal Model & 0.684 \\
\hline
\end{tabular}

Note. $\mathrm{GoF}=$ The Goodness-of-Fit.

To confirm the factor structure of the research model and to verify convergent validity, we proceeded to the computation of the Average Variance Extracted (AVE). The value of the AVE must be superior to 0.5. In addition, in order to verify the reliability of the model's latent variables, we resorted to the computation of Dillon and Goldstein Rho (PCA) which must be larger than 0.7 (Vinzi, Trinchera, \& Amato, 2010). The results of convergent validity and of reliability are displayed in Table 2 below. They reveal that the Dillon and Goldstein 
Rho (PCA) values and the AVE values confirm the unidimensional nature and the reliability of the retained latent variables. To test the discriminant validity of the variables, we proceed to the computation of discriminant validity (Shared variance < AVE). According to Rich (1997), as long as the values of shared variances are inferior to those of the AVE, the discriminatory nature of indicators is confirmed, which has been the case for the indicators of the research model.

Table 2 . Test reliability and convergent validity of the latent variables

\begin{tabular}{|c|c|c|}
\hline Latent variables & PCA & AVE \\
\hline \multicolumn{3}{|l|}{ Socio-Cultural factors } \\
\hline Individual traits and social network & 0.772 & 0.612 \\
\hline Power distance & 0.867 & 0.739 \\
\hline Individualism/Masculinity & 0.890 & 0.723 \\
\hline Development of entrepreneurial skills & 0.870 & 0.569 \\
\hline Society's way of life & 0.867 & 0.620 \\
\hline Ethical atmosphere \& religion values & 0.869 & 0.741 \\
\hline \multicolumn{3}{|l|}{ Economic factors } \\
\hline Transparency \& availability of data and information & 0.856 & 0.644 \\
\hline Promotion of CSR & 0.879 & 0.620 \\
\hline Business plan \& quality assurance process & 0.872 & 0.589 \\
\hline Company's resources management & 0.891 & 0.558 \\
\hline Professional network \& support structure & 0.873 & 0.610 \\
\hline \multicolumn{3}{|l|}{ Legal factors } \\
\hline Entrepreneurial regulation \& public support structures & 0.847 & 0.892 \\
\hline Control system \& bureaucracy & 0.817 & 0.844 \\
\hline \multicolumn{3}{|l|}{ Development of the ethical orientation } \\
\hline Individual level & 0.893 & 0.806 \\
\hline Organizational level & 0.800 & 0.706 \\
\hline Stakeholders' level & 0.811 & 0.763 \\
\hline \multicolumn{3}{|l|}{ Phases of the entrepreneurial process } \\
\hline Triggering of the entrepreneurial process & 0.823 & 0.714 \\
\hline Entrepreneur's total commitment & 0.873 & 0.641 \\
\hline Survival \& growth of the launched business & 0.855 & 0.584 \\
\hline
\end{tabular}

Note. $\mathrm{PCA}=$ Dillon and Goldstein Rho; $\mathrm{AVE}=$ The Average Variance Extracted.

\subsubsection{Confirming Research Hypotheses}

The analysis of statistical results related to the structure model by using the structural equations method, and according to the PLS approach, is displayed in figure 2 below: 


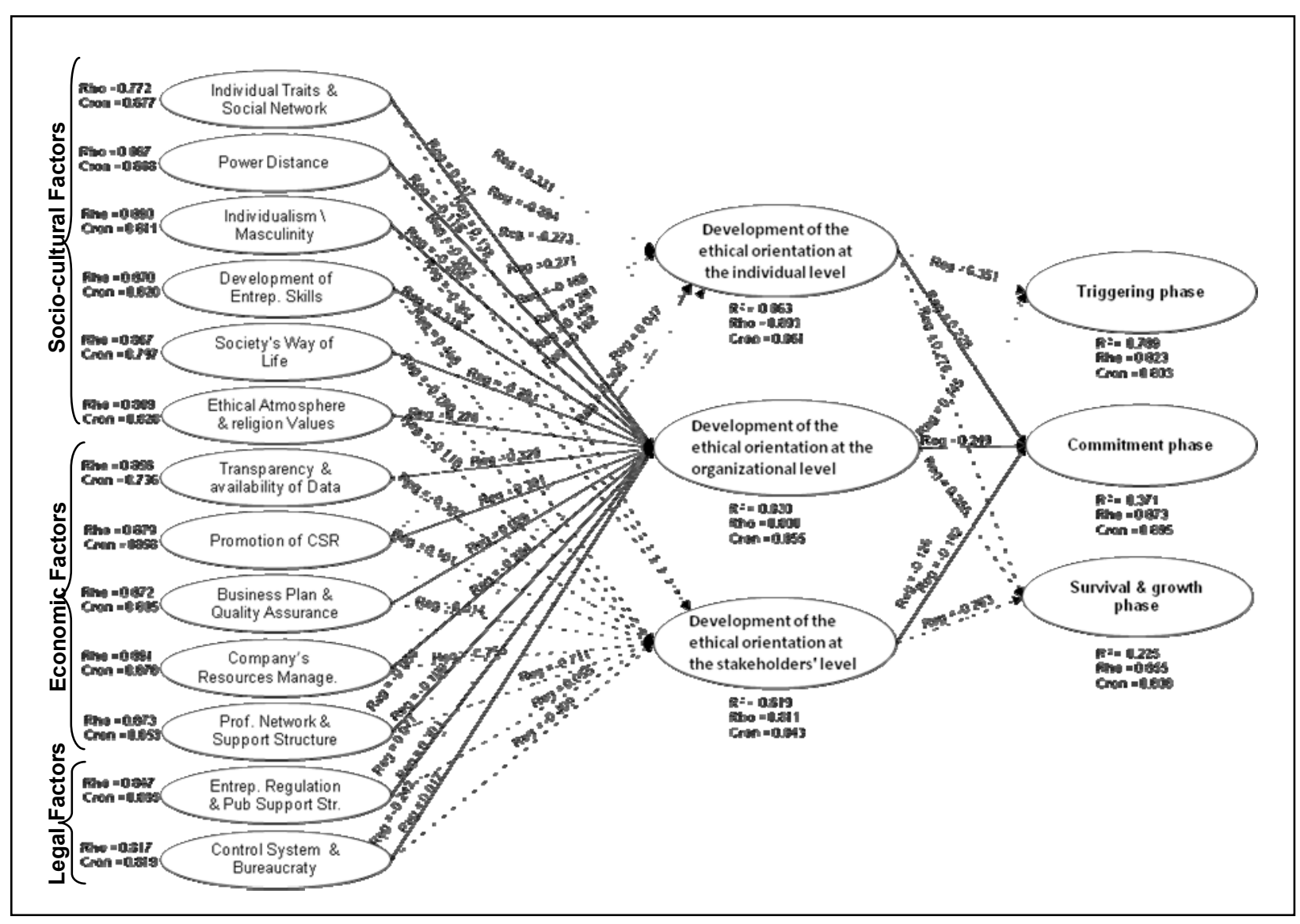

Figure 2. Model structure after estimation

The results of the structure model after assessment show that the Squared Multiple Correlations $\left(\mathrm{R}^{2}\right)$ values of the latent variables relating to ethical evolution at the levels of the individual, the organization, and the stakeholders are high. These latent variables are well explained. The $\mathrm{R}^{2}$ values of latent variables related to the phases of the entrepreneurial process are low, or even very low; "Triggering Phase" (0.371) and "Survival \& Growth Phase" $(0.225)$. It is possible to consider that those variables are not explained.

In order to verify these results, an analysis of significance for regression relationships has been carried out. This analysis shows that the regression links between the variables of development in business ethics at the levels of the individual, the organization, the stakeholders and the other latent variables (socio-cultural, economic, and legal) are significant, with a threshold value of $5 \%$ (Critical Ratio 1.96). This also applies to the regression links between the entrepreneurial process and the explanatory variable labeled "individual level" where the values are significant with a threshold value of 5\% (Critical Ratio 1.96). However, the regression links between the phases of the entrepreneurial process and the other latent variables; "organizational level" and "stakeholders' level" are not significant with a threshold value of 5\% (Critical Ratio 1.96).

This result does not mean the rejection of hypothesis (H4), but requires explanation. The results of the structure model after assessment show that the $\mathrm{R}^{2}$ values of the latent variables relating to ethical evolution at the levels of the individual, the organization, and the stakeholders are high. These latent variables are clearly explained.

\section{Interpretation of Results}

After having tested the reliability of the retained variables and confirmed the research hypotheses, it is important to explain the impact of socio-cultural, economic, and legal factors on the development of business ethics. On the other hand, we analyze the influence of the development of business ethics on the entrepreneurial process.

\subsection{Influence of Socio-Cultural Factors on the Development of Business Ethics}

Individual traits and social network constitute the factor motivating the development of business ethics at the individual level $($ Regression $=0.331$; Critical Ratio $=3.727)$ and the organizational level $($ Regression $=0.247$; Critical Ratio $=2.412$ ). Entrepreneurship is not a spontaneous behaviour in the respondents' character; it is 
rather influenced by their personal traits: gender and age at the time they launched their business project. Despite the funding problems faced by all the surveyed entrepreneurs, along with the numerous handicaps associated with the status of female entrepreneurs, the respondents are ready to face the challenge and proceed to the act of launching their own business.

For $83 \%$ of the surveyed entrepreneurs, the social network constitutes not only a source of assistance and funding for the project, but also a space for mentorship and support for entrepreneurial dynamics. The family, particularly the father, the mother, and the partner, along with friends have an influence on young entrepreneurs. They inspire them, transmit certain values to them, support them, and shape attitudes which are favorable to entrepreneurial behavior.

The regression links between "the development of entrepreneurial skills" and the development of business ethics are significant and positive: at the level of the individual (Regression $=0.271$; Critical Ratio $=2.473$ ); at the organizational level (Regression $=0.315$; Critical Ratio $=3.742$ ); and at the level of stakeholders (Regression $=$ 0.468 ; Critical Ratio $=4.542$ ) . The most frequently cited skills by our respondents are: the determination and enthusiasm for taking action to launch a business enterprise, the ability to identify business opportunities, having one's behavior oriented towards searching information, the decision-making skills, and the skill of facing and challenging the uncertainty and ambiguity which surround the project. The majority of respondents consider that such skills are acquired and improved through observation and experience during the entrepreneurial process.

Correlations between the ethical atmosphere and religion and the development of the ethical orientation at the individual level (Regression $=0.261$; Critical Ratio $=2.096$ ), on the one hand, and the organizational level (Regression $=0.228$; Critical Ratio $=2.188$ ), on the other hand, is both positive and significant. Respondents mentioned the positive divine instructions prohibiting dishonesty, theft, laziness, passivity, and encouraged diligence, denunciation and blame for any act of violation, and dedication in the workplace. They consider that the degree of commitment to such values dependent on personal faith and convictions.

The data analysis of other socio-cultural factors shows that power distance, individualism, masculinity, and society's way of life have a significant and negative influence on the development of business ethics. In fact, $48 \%$ of the respondents consider that their business projects are launched in a society characterized by a marked social distance (Regression $=-0.284$; Critical Ratio $=-1.979$ ) which can be explained by social inequality between regions, unequal distribution of national resources, and unequal regional development. Entrepreneurs coming from different regions in the country do not have equal access to advantages, such as access to funding facilities and to support structures whose role is to reinforce the setting up of business projects. Furthermore, they do not have access to the same infrastructure required for launching and promoting their projects.

The correlation is negative between individualism/masculinity and the development of business ethics at the individual level (Regression $=-0.273$; Critical Ratio $=-2.450$ ), the organizational level $($ Regression $=-0.206$; Critical Ratio $=-1.989$ ) and the stakeholders' level (Regression $=-0.364$; Critical Ratio $=-2.300$ ). The respondents' identity and values are grounded in their self-satisfaction (practice of specialism, improvement of income, social status, and independence) rather than in the social system as such. The resources management of the firm is carried out on an individual basis and is result-oriented. Focal importance is accorded to the values of success and ownership. In their relationships with stakeholders, individual interest has priority over collective interest. Societal culture, which is characterised by individualism and masculinity, and in which entrepreneurial projects are being launched, seems to be inappropriate for maintaining and developing the ethical orientation of entrepreneurship.

A societal culture privileging the entrepreneur's unethical behavior is also a consequence of a whole way of life in the society of which the entrepreneur is a member and in which his/her project is launched and promoted. Data analysis indicates that the correlation is negative between the way of life and the development of business ethics at the individual level (Regression $=-0.188$; Critical Ratio $=-2.276$ ), the organizational level (Regression $=-0.293$; Critical Ratio $=-2.636)$ and the stakeholders' level $($ Regression $=-0.780$; Critical Ratio $=-2.914)$. According to respondents, entrepreneurs, salaried employees, and stakeholders spend much more money than they can afford with just their income, resorting to loans and certain unethical practices. Regionalism and loyalty to tribal relations or parental ties can eclipse the responsibilities of an entrepreneur leading a project. Thus, the entrepreneur becomes the first victim of this social system. In fact, $52 \%$ of the respondents raised the problem of the existence of dishonest and delinquent untouchables who divert funds without leaving any trace or evidence proving their illegal transactions. Our respondents emphasized the unethical behavior of competitors and public officials (fiscal division staff, customs staff, etc.).

Data analysis of socio-cultural factors has verified the first hypothesis related to the impact of the socio-cultural 
environment on the development of the ethical orientation at the levels of the individual, the organization, and the stakeholders.

\subsection{The Impact of Economic Factors on the Development of Business Ethics}

The correlation between transparency and the availability of data and information, on the one hand, and the development of the ethical orientation, on the other, is positive at the organizational level (Regression $=0.329$; Critical Ratio $=3.269)$, and negative at the stakeholders' level (Regression $=-0.302$; Critical Ratio $=-2.636$ ).

At the organizational level, according to $46 \%$ of the respondents, decision-making and exchange of information are both handled in conformity with transparent, simple, and intelligible procedures which duly respect responsibility and initiative-taking. According to them, transparency is crucial for an efficient management for the firm's resources and for fighting all types of unethical behavior. Concerning the relationships between stakeholders and the project designer, information asymmetry and lack of transparency prevail. The majority of young entrepreneurs mentioned the difficulties related to their access to funding resources which can assist them in launching and developing their business enterprise, developing new products, and investing in raw recruits and in new production sites. Commercial banks particularly avoid providing funds for these young entrepreneurs because they fail to offer sufficient bank loan guarantee.

Obstacles preventing their entry to the world of entrepreneurial enterprise, such as the restriction imposed on young entrepreneurs to cope with the costs which are structurally and durably higher than those handled by firms already in operation, as well the response potential of operating firms in reaction to newcomers, represent threats impeding both the survival and the promotion of their business enterprise. The barriers mentioned by respondents are multiple and diverse: legal barriers (regulations and red tape in a bureaucratic administration), industrial (scale economy), technological (costs of procurement of new technological equipment), fiscal (heavy taxation), economic (cost of initial financing in investment), and commercial (sale problems and unfair competition). Other obstacles can be added: lack of skills on the labor market, absence of clear and official procedures for resources management in business firms, and suppliers' inefficiency. All these barriers and obstacles have led to inefficiency in resources management in the firm and also to insufficiency in the professional network which has a negative correlation with the development of business ethics at the organizational level (Regression $=-0.284$; Critical Ratio $=-2.758)$ and at the level of stakeholders (Regression $=$ -0.711; Critical Ratio $=-3.851$ ). In the future, such barriers will be aggravated for the surveyed small business firms; and consequently, the young entrepreneurs might be tempted to act in discord with ethical rules.

Seventy-two percent (72\%) of respondents emphasized their social responsibility towards their business partners. They mentioned multiple examples of good practices where the social, ecological, and economic aspects are kept in harmony. Such practices have contributed to cohesion and to the enhancement of the spirit of responsibility and participation among the employees in the process of initiating and promoting the enterprise. This explains the positive correlation between social responsibility and business ethics at the organizational level $($ Regression $=0.301$; Critical Ratio $=2.004)$.

Thirty-seven percent $(37 \%)$ of the respondents consider that the business plan represents a tool for persuading financial donors to grant funds for lunching business firms. This tool does not include any preoccupations of an ethical nature.

For all the business firms surveyed, it is worth noting the absence of any quality approach applied in order to evaluate programs, procedures, and practices. This can be explained by the lack of skills and material resources.

The results of data analysis of the relationships between the economic factors and the development of business ethics verify the second research hypothesis (H2) about the effects of the economic environment on the development of ethical orientation at the individual, organizational and stakeholders' levels.

\subsection{The Impact of Legal Factors on the Development of Business Ethics}

As to entrepreneurial regulation and public support structures, the survey reveals that $67 \%$ of respondents have benefited from financial privileges as well as fiscal and para-fiscal exemptions. These advantages have motivated young entrepreneurs, during the first two years, to concentrate their efforts on launching the project and maintaining their business (Regression $=0.303$; Critical Ratio $=2.550$ ). The majority of respondents believe that fiscal policies represent a handicap for the development of their business enterprise. Some of the entrepreneurs have frankly mentioned that they are tempted to avoid paying taxes and adopt fiscal evasion.

Eighty-seven percent $(87 \%)$ of the respondents consider that after having designed their business plan and during the initial phase of starting their business, the first difficulties they encountered were the administrative procedures required for registering their new firm before they can operate legally. They state that the 
administrative file required for establishing a new business is complex and causes various types of delay in starting the firm. According to all the respondents, bureaucracy, red tape, complex administrative procedures, and centralization in decision-making remain the major obstacles which are difficult to overcome (and for many they even impossible to cope with). These obstacles make the young entrepreneurs exposed to difficulties pertaining to starting and managing their business projects, in addition to contributing to the emergence of unethical behavior at the individual level (Regression $=-0.242$; Critical Ratio $=-2.520$ ) and the stakeholders' level, especially public officials and suppliers (Regression $=-0.409$; Critical Ratio $=-2.851$ ).

These results verify our third hypothesis (H3) related to the impact of the legal environment on the development of ethical orientation in relation to the entrepreneurs, the organization, and the stakeholders.

\subsection{The Impact of the Development of Business Ethics on the Entrepreneurial Process}

The results of data analysis show that ethical development at the individual level affects entrepreneurs' behavior during all the phases of the entrepreneurial process: triggering phase (Regression $=0.351$; Critical Ratio $=$ 3.161 ), commitment phase (Regression $=0.228$; Critical Ratio $=2.788$ ) and the survival-growth phase (Regression $=0.276$; Critical Ratio $=2.527$ ). For $93 \%$ of the respondents, setting up a business is a matter of life project. The surveyed entrepreneurs are not willing to sacrifice their social life, as they intend to help their social environment and contribute to local wealth through creating jobs and offering services to the community. The leadership style used by the surveyed entrepreneurs is heterogeneous, as they sometimes use authority and control and some other times they use understanding, communication, and participative leadership. Most of them seek to improve working conditions, integrate employees in the decision-making process, and take advantage of career development opportunities.

Thus, it is clear that the ethical dimension in business enterprise occupies an important position in the entrepreneurs' perspective. Relations with partners, whether they are customers, suppliers, or public officials, do not seem to be immune from difficulties. The professional environment is mainly blamed for the problems associated with reinforcing business partners' integrity, the promotion of transparency, and the process of negotiation in a constructive and moral way. The surveyed entrepreneurs also mentioned the problem of the presence of consumer workers, the pressure exerted by competitors to undertake illicit actions, and sexual harassment in the special case female entrepreneurs. This proves that quite beyond its rational, instrumental and social nature, entrepreneurship seems to be a process closely connected to a system of norms and values pertaining to business ethics.

As to the ethical development at the organizational level, it seems that its impact is not strong throughout all the phases of the entrepreneurial process: triggering phase (Regression $=0.145$; Critical Ratio $=1.110$ ), commitment phase $($ Regression $=0.149$; Critical Ratio $=1.186)$ and survival-growth phase $($ Regression $=0.155$; Critical Ratio $=1.311$ ). The same applies to ethical development at the stakeholders' level, which has a weak influence during the entrepreneurial process: triggering phase (Regression $=0.126$; Critical Ratio $=0.938$ ) commitment phase $($ Regression $=0.192$; Critical Ratio $=1.334)$ and survival-growth phase $($ Regression $=0.163$; Critical Ratio $=0.910$ ).

During the commitment phase, while launching their own business enterprise, entrepreneurs engage in the feasibility study of their project through designing a business plan. The entrepreneurial project takes shape and becomes legitimate once optimal resources are assembled and deployed. As pointed out by one of the respondents, 'At this phase, my main concern is to design a business plan which can convince the stakeholders, especially those who are ready to finance my project.' For fear of facing certain irreversible scenarios, the entrepreneur generally tries to neutralize all the difficulties and resolve all the problems which are likely to disturb the efficient creation of his/her own business enterprise. The surveyed entrepreneurs mentioned the problems of lack of financial resources, in addition to ambiguities and paradoxes. It seems that ethical development at the organizational and stakeholders' level has no place during this phase since the firm has not yet taken shape and the relationship with partners is left for the feasibility study of the project both financially and legally.

During the survival-growth phase, while launching their own business enterprise, entrepreneurs engage in daily activities and should demonstrate their efficiency and effectiveness. For $82 \%$ of the surveyed entrepreneurs, mastering the development of the new business enterprise is a challenging task. The most frequently mentioned problems are related to sales, how to gain the customers' and suppliers' confidence, how to optimize the management of resources, and how to challenge new horizons for the project. The entrepreneurs also pointed out that the business enterprise becomes a routine phenomenon which they try hard to escape: 'At the beginning, it was an enterprise undertaken by a creative entrepreneur endowed with a spirit of challenge; but today [during 
the survival-growth phase] it has to do with managerial tasks.' Their ethical considerations eventually enter into conflict with the logic of ensuring efficient and effective management of the firm's resources.

When asked in a straightforward way about the ethical issue, the surveyed entrepreneurs claimed that attitude and action are two inseparable phenomena. The entrepreneur is judged on the basis of his/her actions and values, but his/her attitudes and convictions belong to him/her; he/she is the only person who is entitled to assess them. For the surveyed entrepreneurs, business ethics is considered like a feeling of social belonging. It particularly emphasises the entrepreneur's morals and still remains ambiguous, vacillating between idealism (ethics of duty) and utilitarianism.

According to the analysis of these results, the fourth hypothesis related to the role of developing ethical thinking in the phases of the entrepreneurial process has been verified.

\section{Conclusion}

Commitment to the entrepreneurial process is conceived as a rational behavior aiming at maximizing opportunities (economic rationality), a normative mode of reasoning (regulations), a way of integrating into a social track (socialization), and a theme characterized by reflexivity (individual ethics). The entrepreneur implements these various logics of action within the framework of a convenient justificatory model which assigns meaning to the entrepreneurial act. Thus, the development of ethical orientation constitutes one of the dimensions to be accounted for during the entrepreneurial process. It remains subject to the socio-cultural, economic, and legal specificities of the environment in which the entrepreneur lives, and it influences the choice of the entrepreneurial career and managerial decisions.

The survey conducted on a population of 57 young Tunisian entrepreneurs has shown that entrepreneurship is influenced by individual traits and various socio-cultural, economic, and legal factors. The presence and the influence of these factors differ from one phase to another in the entire entrepreneurial process. Ethical development at the individual level has a strong influence on all the phases of the entrepreneurial process. However, at the organizational and stakeholders' levels, ethical behavior has a weak influence on the entrepreneurial process insofar as ethical norms and values are not formalized. The surveyed entrepreneurs feel satisfied with prohibiting unethical behavior and applying sanctions. A considerable gap has been noticed between emergent culture and deliberate culture, which allows for the possibility of tracing reference points to help business partners act ethically.

Referring to the models of Di Norcia (1998) and Clarkson (1995), the surveyed entrepreneurs implicitly adopt a reactive or defensive strategy. They aim at interdicting unethical behavior through imposing sanctions on salaried employees and warning external partners (suppliers, customers, public officials). The elaboration of ethical codes - as proposed by (Adams, Tashchian, \& Shore, 2001) - and the adoption of a proactive strategy — following Clarkson (1995) - seem to be important tools for making business ethics a dynamic, continuous, and endless process (Svensson \& Wood, 2008).

\section{References}

Adams, J. S., Tashchian, A., \& Shore, T. H. (2001). Codes of Ethics as Signals for Ethical Behavior. Journal of Business Ethics, 29, 199-211. http://doi.dx.org/10.1023/A:1026576421399

Baucus, M. S., \& Near, T. J. (1991). Can Illegal Corporate Behavior Be Predicted? An Event History Analysis. Academy of Management Journal, 34(1), 9-36.

Bruyat, C. (1993). Entrepreneurship: epistemological contributions and modeling. Unpublished doctoral dissertation, Pierre Mondès University, Business Management School.

Bygrave, W. D. (2010). The Entrepreneurial Process. In W. D. Bygrave \& Z. Andrew (Eds.), The Portable MBA in Entrepreneurship (pp. 1-26). Wiley, Hoboken, NJ. http://doi.dx.org/10.1002/9781118256121.ch1

Clarkson \& Max, B. E. (1995). A stakeholder framework for analyzing and evaluating corporate social performance. Academy of Management Review, 20(1), 92-117. http://doi.dx.org/10.5465/AMR.1995.9503271994

Di Norcia, V. (1998). Hard like Water: Ethic in Business. Toronto: Oxford University Press.

Dubet, F. (1994). Sociology of experience. Seuil editions, Paris, France.

Fayolle, A. (2005). Evaluation of entrepreneurship education: behaviour performing or intention increasing? International Journal of Entrepreneurship and Small Business, 2(1), 89-98. http://doi.dx.org/10.1504/IJESB.2005.006072 
Gasse, Y. (2002). Functional Diversity in University Entrepreneurship Development: The Laval University Model. In V. M. Teresa (Ed.), Entrepreneurship and the Canadian Universities (pp. 71-76). St. Catharines, Ont., Brock University.

Gasse, Y., \& Tremblay, M. (2006). Entrepreneurship education among students at a Canadian university: an extensive empirical study of students entrepreneurial preferences and intentions. In A. Fayolle \& H. Klandt (Eds.), International entrepreneurship education: issues and newness (pp. 241-262). Edward Elgar, Cheltenham, UK.

Greenberger, D. B., \& Sexton, D. L. (1988). An interactive model of new venture initiation. Journal of Small Business Management, 26(3), 1-7.

Hofstede, G. (1980). Culture's consequences: international differences in work-related values. Beverly Hills, CA: Sage.

Kohlberg, L. (1981). Essays on moral development. San Francisco: Harper and Rows.

Kolvereid, L., \& Isaksen, E. (2006). New business start-up and subsequent entry into self- employment. Journal of Business Venturing, 21(6), 866-885. http://doi.dx.org/10.1016/j.jbusvent.2005.06.008

Learned, K. E. (1992). What Happened Before the Organization? A Model of Organization Formation. Entrepreneurship: Theory and Practice, 17(1), 39-48.

Lichtenstein, B. M., Smith, B. A., \& Torbert, W. R. (1995). Leadership and ethical development: Balancing light and shadow. Business Ethics Quarterly, 5(1), 97-116.

Maclagan, P. (1998). Management \& Morality: A Developmental Perspectives. London: Sages Publications.

Martin, J. S., \& Novicevic, M. (2010). Social entrepreneurship among Kenyan farmers: A case example of acculturation challenges and program successes. International Journal of Intercultural Relations, 34, 482-492. http://doi.dx.org/10.1016/j.ijintrel.2010.05.007

Mayer-Schönberger, V. (2010). The Law as Stimulus: The Role of Law in Fostering Innovative Entrepreneurship. A Journal of Law and Policy, 6(2), 153-188.

Minniti, M., \& Bygrave, W. (2001). A Dynamic Model of Entrepreneurial Learning. Entrepreneurship: Theory and Practice, 25(spring), 5-16.

Nitkin, D., \& Brooks, L. J. (1998). Sustainability auditing and reporting: The Canadian experience. Journal of Business Ethic, 17, 1499-1507. http://doi.dx.org/10.1023/A:1006044130990

Nordin, R. M., Takim, R., \& Nawawi, A. H. (2012). Transparency Initiative (TI) in Construction: The Social Psychology of Human Behaviours. Procedia-Social and Behavioral Sciences, 50, 350-360. http://doi.dx.org/10.1016/j.sbspro.2012.08.040

Rich, G. A. (1997). The Sales Manager as a role model: Effects on trust, job satisfaction, and performance of salespeople. Academy of Marketing Science Journal, 25(4), 319-328. http://doi.dx.org/10.1177/0092070397254004

Schumpeter, J. A. (1934). The Theory of Economic Development. Cambridge, MA: Harvard University Press.

Shane, S., \& Venkataraman, S. (2000). The Promise of Entrepreneurship as a Field of Research. Academy of Management Review, 25(1), 217-226. http://doi.dx.org/10.5465/AMR.2000.2791611

Shook, C. L., Priem, R. L., \& Mcgee, J. E. (2003). Venture Creation and the Enterprising Individual: A Review and Synthesis. Journal of Management, 29(3), 379-399. http://doi.dx.org/10.1016/S0149-2063(03)00016-3

Svensson, G., \& Wood, G. (2008). A Model of Business Ethics. Journal of Business Ethics, 77, 303-322. http://doi.dx.org/10.1007/s10551-007-9351-2

Vinzi, V. E., Trinchera, L., \& Amato, S. (2010). PLS Path Modeling: from Foundations to Recent Developments and Open Issues for Model Assessment and Improvement. In V. E. Vinzi, W. W. Chin, J. Henseler \& H. Wang (Eds.), Handbook of Partial Least Squares: Concept, Methods and Applications (pp. 47-82). Springer-Verlag, Berlin.

Wells, D., \& Schminke, M. (2001). Ethical development and human resources training an integrative framwork. Human Resource Management Review, 11, 135-158. http://doi.dx.org/10.1016/S1053-4822(00)00044-9

Wood, D. J. (1991). Corporate Social Performance Revisited. Academy of Management Review, 16(4), 691-718. http://doi.dx.org/10.5465/AMR.1991.4279616 


\section{Copyrights}

Copyright for this article is retained by the author(s), with first publication rights granted to the journal.

This is an open-access article distributed under the terms and conditions of the Creative Commons Attribution license (http://creativecommons.org/licenses/by/3.0/). 